\title{
Factors of Consumer Behavior Effected the Use of Tesco Lotus Credit Card, Bangkok
}

\author{
Dr. Chairat Suriyapa, and Aiyada Luecha \\ arjarnchairat@gmail.com \\ Postgraduate school of business administration, Kasembundit University, Bangkok
}

\begin{abstract}
The purpose of this study is to determine factors of consumer behavior and marketing mix effected the use of Tesco Lotus credit card.The samples were selected from 400 Tesco Lotus credit card users by using a check list and rating scale questionnaire as a tool. Statistical application used for data analysis was percentage, mean, standard deviation, and t-test, Chi Square, and regression analysis.

Findings from the study indicated that most of respondents were females, age between 31-40 years old, bachelor degree or equivalent graduated, single marital status, private companies employees, and monthly income between 20,000-30,000 baht. Most of users used Visa gold credit card for shopping or merchandise payments. Self-decision making after persuaded by sale representative and applied for Tesco Lotus credit card at counter service. Frequency of Tesco Lotus credit card used average of 3.50 times monthly. Satisfied with higher credit returned rate than competitorswhen purchasing merchandises with Tesco Lotus credit card.

Factors of marketing mix effectedconsumer behavior on the use of Tesco Lotus credit card with average picture of opinions were at high level consisted of following aspect: as of products aspect, the variety benefit from usage, post purchasing, free of service fee for first year, appropriate approval credit limit, low interest, applicable service fee. As for distribution channel aspect, location to apply for credit card with conveniently access, diversity of cash advance.As for marketing promotion aspect, cash back with purchasing limit, and discount prices when using credit card with merchant members. As for the service aspect, fast credit approval. As for personnel aspect, personnel pay attention to customers, and finally satisfactory service area for the service. Hypothesis testing revealed that factors of personal different such as, gender and occupation affected consumer behavior on the use of Tesco Lotus credit card and factors of marketing mix, such as products, prices, marketing promotion, personnel, and service process correlated to consumer behavior on the use of Tesco Lotus credit card with statistical significant level 0.05.

Recommendations from this study were that administrative officers should focus on brand image, service fee or free of charge, increase distribution channel, marketing promotion by creating event to offer new products, set up promotion booth for example, competent personnel who are knowledgeable regard credit benefit, service with appropriate time, and service area with clean environment.
\end{abstract}

Keywords: Consumer, Tesco Lotus, Credit Card, Bangkok

\section{Introduction}

Tesco Lotus financial services operated by Tesco card services Co., Ltd. and Tesco General Insurance Broker Co., Ltd., which offers financial and insurance services. Established by GE Capital Co., Ltd., Thailand and changed company name to Ayuthaya Capital Services and shareholders with Eak-Chai distribution Co., Ltd., since 2547.

Head office located at $87 / 2$ all seasons Capital towers, $10^{\text {th }}$ floor, Withayu road,Lumpini District, Patumwan area, Bangkok 10330. Currently, company offers financial and insurance service counter inside 150 Tesco Lotus Co., Ltd., branches nationwide.In addition, offered telephone service at 1712 number and internet service began 
on third quarter of year 2553. The company focus on giving service to customers to receive most benefit when they use their credit cards.

Tesco Lotus offered with 3 different cards, such as Tesco Lotus credit card, visa credit card, and platinum credit card which are used visa pay wave technology for customer convenient and accumulate points limit to redeem for cash refund.

As from information mentioned above, researcher is interested in studyingfactors of consumer behavior and marketing mix effected the use of Tesco Lotus credit card and consumption of therevealed to set a guideline to improve the services for Tesco Lotus credit card division.

\section{Literature Review}

The first four elements in the services marketing mix are the same as those in the traditional marketing mix. However, given the unique nature of services, the implications of these are slightly different in case of services.(MarGrath, 1986).

1. Product: In case of services, the 'product' is intangible, heterogeneous and perishable. Moreover, its production and consumption are inseparable. Hence, there is scope for customizing the offering as per customer requirements and the actual customer encounter therefore assumes particular significance. However, too much customization would compromise the standard delivery of the service and adversely affect its quality. Hence particular care has to be taken in designing the service offering.

2. Pricing: Pricing of services is tougher than pricing of goods. While the latter can be priced easily by taking into account the raw material costs, in case of services attendant costs - such as labor and overhead costs also need to be factored in. Thus a restaurant not only has to charge for the cost of the food served but also has to calculate a price for the ambience provided. The final price for the service is then arrived at by including a markup for an adequate profit margin.

3. Place: Since service delivery is concurrent with its production and cannot be stored or transported, the location of the service product assumes importance. Service providers have to give special thought to where the service would be provided. Thus, a fine dine restaurant is better located in a busy, upscale market as against on the outskirts of a city. Similarly, a holiday resort is better situated in the countryside away from the rush and noise of a city.

4. Promotion: Since a service offering can be easily replicated promotion becomes crucial in differentiating a service offering in the mind of the consumer. Thus, service providers offering identical services such as airlines or banks and insurance companies invest heavily in advertising their services. This is crucial in attracting customers in a segment where the services providers have nearly identical offerings. We now look at the 3 new elements of the services marketing mix - people, process and physical evidence - which are unique to the marketing of services.

5. People: People are a defining factor in a service delivery process, since a service is inseparable from the person providing it. Thus, a restaurant is known as much for its food as for the service provided by its staff. The same is true of banks and department stores. Consequently, customer service training for staff has become a top priority for many organizations today.

6. Process: The process of service delivery is crucial since it ensures that the same standard of service is repeatedly delivered to the customers. Therefore, most companies have a service blue print which provides the details of the service delivery process, often going down to even defining the service script and the greeting phrases to be used by the service staff.

7. Physical Evidence: Since services are intangible in nature most service providers strive to incorporate certain tangible elements into their offering to enhance customer experience. Thus, there are hair salons that have well designed waiting areas often with magazines and plush sofas for patrons to read and relax while they await their turn. Similarly, restaurants invest heavily in their interior design and decorations to offer a tangible and unique experience to their guests. 


\section{The purpose of the Study}

1. To study consumer behavior of the use of Tesco Lotus credit card.

2. To studyfactors of consumer behavior effect the use of Tesco Lotus credit card

\section{Conceptual frameworks of the Study}

Conceptual frameworks of the study which show relationship between independent variables and dependent variable as follow:

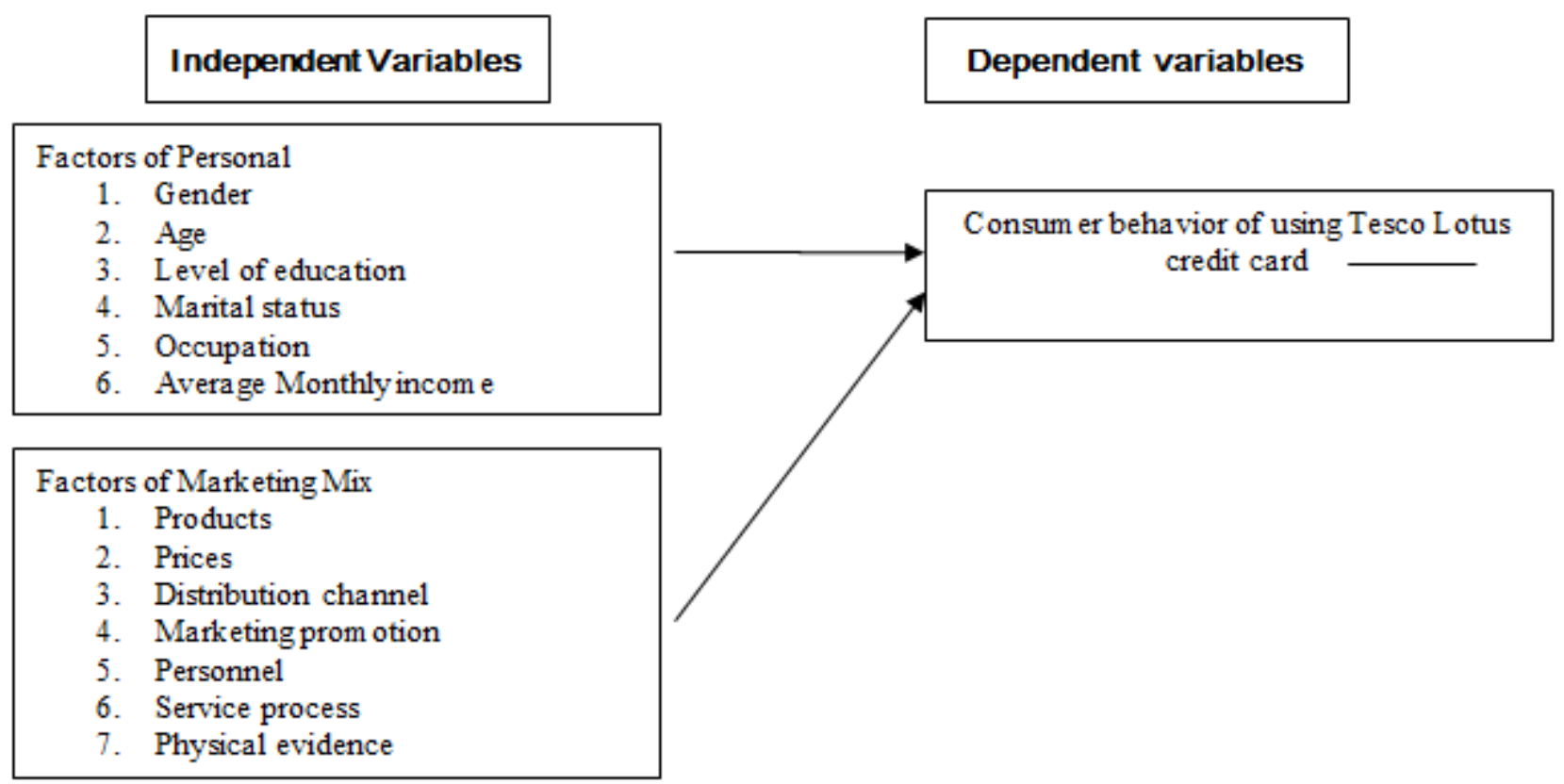

\section{Research Methodology}

\subsection{Sample Selection}

The samples were selected from 400 Tesco Lotus credit card users

\subsection{Data collection Procedure}

The questionnaires were distributed to sample of 400Tesco Lotus credit card users. A total of 400 usable questionnaires were returned back to the researcher, yielding a 100 percent response rate and no missing data.

\subsection{Results of the Study}

\section{Personal data}

Findings from the study indicated that most of respondents were females, age between 31-40 years old, bachelor degree or equivalent graduated, single marital status, private companies employees, and monthly income between 20,000-30,000 baht.

\section{Consumers' behavior of the use of Tesco Lotus credit card}

The study revealed that most of respondents using gold visa Tesco Lotus credit cards for merchandises purchased and bills payment, applied credit application at Tesco Lotus counter service, frequency of credit card used 3.5 times monthly, self-decision making on applied for credit card afterpersuaded by sale representative, satisfied with higher credit returned rate than competitors when purchasing merchandises with Tesco Lotus credit card. 
Factors of marketing mixeffect consumer behavior on the use of Tesco Lotus credit card

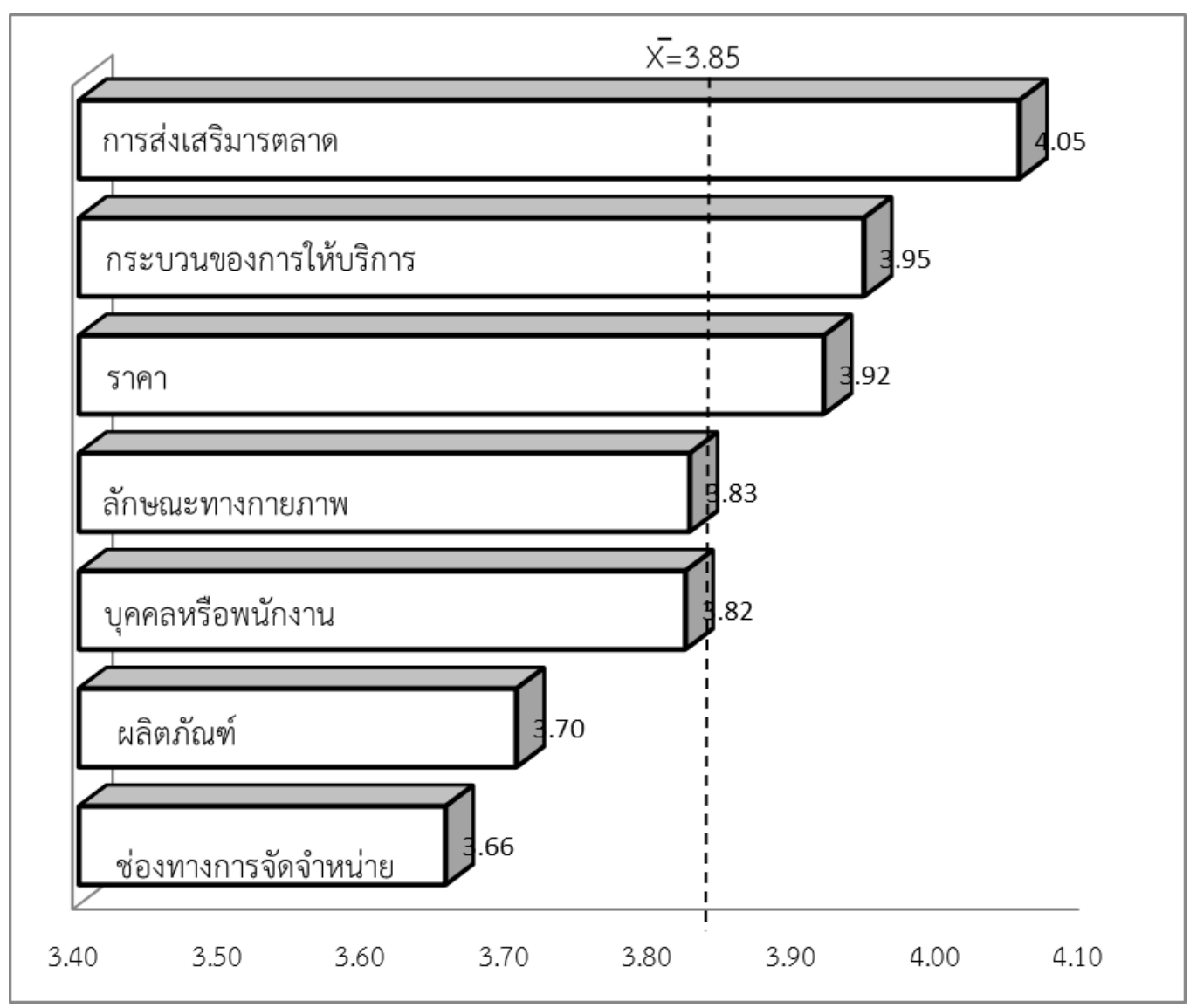

\section{Results from the study}

Factors of marketing mix effected consumer behavior on the use of Tesco Lotus credit card revealed that products aspect with average picture of opinion were in high level considered, such as a diversity of benefit of using Tesco lotus credit card, post purchased, discount prices for repeated customers, and reserved appropriate parking spaces for credit card users.

As for price aspect with average picture of opinions were in high level, such as free application fee for the first year of use, appropriate credit approval limit, low interest, and reasonable credit card usage service fee.

For distribution channelwith average picture of opinions were in high level, such as variety of distribution channel, diversity of cash advance locations, and places to pay credit card bills.

For marketing promotion with average picture of opinions were in high level, such as higher value of cash back, inform customers when new products offering, and free gift when apply for a credit card.

Asfor customers service by personnel with average picture of opinions were high level, such as spotless uniform, response to customer demand with courtesy and accurately.

As for service process with average picture of opinions were in high level, such as rapidly and accurately approval of credit, returned merchandise and refund with convenient, gift redemption, accepting credit application with appropriate places.

As for physical evidencewith average picture of opinions were in high level, such as adequate service area, cleanliness of counter service, and modern office equipment.

\section{References}

[1] Kannalak Srivichai. (2557). Factors of marketing mix correlated with consumer behavior of using Government Saving Bank in cholburi district, Burapha University publisher. 
[2] KanokmaniMookdasattabut. (2555). The level of opinion of marketing mix of Siam Commercial Bank Co., Ltd. credit card customers, future park branch, Master of Business Administration, Ratchaphatvalailongkorn University.

[3] Kasikorn Thai Bank http://ananmoney.com May 27 search 2559 about the meaning of a credit card.

[4] Tesco Lotus Card Services Co., Ltd., (http://tescolotusfs.com), May 27 search 2559. History of Tesco Lotus card services Co., Ltd.

[5] PattitaKakaradi. (2554). Factors of marketing mix services affecting consumer behavior of Buying merchandise by using credit cards in Bangkok, Master of Business Administration, Srinakarinviroj University publisher.

[6] PorntipVivitanakorn. (2557). Marketing Strategy. Master of Business Administration, Bangkok University.

[7] VarutPrapaipak. (2556). Marketing mix services with the elements. Marketing department, Srinakarinviroj University publisher.

[8] SiriwanSaerirat\& Associate. (2541). New era of marketing management. Terafilm and Chaitex Publisher.SompitTupyung. (2552). KrungsriAyuthayaCo., Ltd., credit card users behaviorKohSamui District, Surajthani province, Master of Business Administration, Valailak University.

[9] HatairatSuwansri. (2556). Factors of relationship with consumer using Bangkok Bank creditCard to purchase merchandise and services in Nakorn Pathom2, Thesis, Master of Business Administration, Silapakorn University.

[10] Kotler, Phillip. (1997). Marketing Management Analysis, Planning, Implementation, and Control P. 172, $9^{\text {th }}$ ed., New Jersey, A simon\& Schuster Company. 